\title{
GMR
}

\section{Comparisons of different myosin heavy chain types, AMPK, and PGC-1 $\alpha$ gene expression in the longissimus dorsi muscles in Bama Xiang and Landrace pigs}

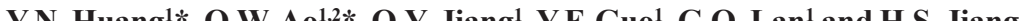

${ }^{1}$ Laboratory of Animal Genetics and Breeding, College of Animal Science and Technology,

Guangxi University, Nanning, China

${ }^{2}$ Guangxi Academy of Fishery Sciences, Nanning, China

*These authors contributed equally to this study.

Corresponding author: Q.Y. Jiang

E-mail: jiangqinyang@hotmail.com

Genet. Mol. Res. 15 (2): gmr.15028379

Received August 8, 2015

Accepted November 26, 2015

Published July 15, 2016

DOI http://dx.doi.org/10.4238/gmr.15028379

ABSTRACT. Bama Xiang and Landrace pigs are the local fatty and lean breeds, respectively, in China. We compared differences in carcass traits, meat quality traits, and myosin heavy chain (MyHC) types in the longissimus dorsi muscles between Bama Xiang and Landrace pigs. This was done in pigs of the same age, using real-time PCR, to investigate the relationship between $\mathrm{MyHC}$ fiber types and carcass characteristics, meat quality traits, and the key factors regulating muscle fiber type. Bama Xiang pigs exhibited smaller size and slower growth than Landrace pigs $(\mathrm{P}<0.01)$. We found that the superior meat quality, especially the high intramuscular fat (IMF) content in Bama Xiang pig, was related to elevated type I oxidative muscle fiber content $(\mathrm{P}<0.01)$. In contrast, Landrace pig muscle had a higher glycolytic type IIb muscle fiber content $(\mathrm{P}<0.01)$. MyHC I gene expression was 
significantly positively correlated with backfat thickness and IMF content $(\mathrm{P}<0.01)$. MyHC IIb was significantly negatively correlated with IMF content $(\mathrm{P}<0.05)$, and positively correlated with carcass yield $(\mathrm{P}<0.05)$. AMP-activated protein kinase and peroxisome proliferatoractivated receptor- $\gamma$ coactivator- $1 \alpha$ are suggested to be the two key factors regulating muscle fiber type in pigs. Our results indicate that muscle fiber composition is one of the key differences leading to the differences of meat quality between Bama Xiang and Landrace pigs. These results may provide a theoretical basis for further studies of the molecular mechanism underlying the excellent meat quality of the Bama Xiang pig.

Key words: Bama Xiang pig; Meat quality; Carcass trait; AMPK; Myosin heavy chain; PGC-1 $\alpha$

\section{INTRODUCTION}

Bama Xiang pig was named after Bama Town in the Guangxi Province in southern China. This breed displays a high reproductive performance, slow-growth, high intramuscular fat (IMF) contents, and superior meat quality. The Landrace pig is famous for its lean meat, fast growth, low IMF content, and poor succulent flavor (Lefaucheur et al., 2002; Shan et al., 2009; Guo et al., 2011). Therefore, these two breeds are two ideal models for research on pig growth performance and meat quality.

Muscle fibers constitute $75-90 \%$ of the muscle (Lee et al., 2010) and largely determine the characteristics of the muscle. Skeletal muscles of growing pigs consist of four muscle fiber types: type I, IIa, IIx, and IIb, which are based on myosin heavy chain (MyHC) polymorphisms (Lefaucheur et al., 2002). Types I and IIa are considered to be oxidative fibers, with a high mitochondrion and myoglobin contents and appear rosy in color (Pette and Staron, 2001; Lefaucheur, 2010). Type IIb is considered to consist of glycolic fibers, producing a pale, soft, and exudative meat (Wegner et al., 2000). In recent years, a number of key genes regulating muscle fiber type transition have been identified, such as peroxisome proliferator-activated receptor- $\gamma$ coactivator- $1 \alpha$ (PGC-1 $\alpha$ ) (Lin et al., 2002), AMP-activated protein kinase (AMPK) (Röckl et al., 2007), etc.

At present, there are no studies of the composition and postmortem muscle metabolism of Bama Xiang pigs. In the current study, we set out to compare the differences in carcass traits, meat quality traits, and muscle fiber types between Bama Xiang and Landrace pigs of the same age. Our aim was to identify the relationship between MyHC fiber types and carcass and meat quality traits, and to investigate the key factors regulating the muscle fiber type in the two breeds. Our study provides a better understanding for the molecular mechanism behind the excellent Bama Xiang pig meat quality.

\section{MATERIAL AND METHODS}

All parts of our study were carried out following the guidelines for animal experiments at the National Institute of Animal Health in China (License No. GB/T 14925-94). 


\section{Animal and sample collection}

Fifteen Bama Xiang pigs and 12 Landrace pigs were raised for our study. The animals were kept under similar conditions and were fed the same diet (NY/T 65-2004, Chinese Ministry of Agriculture). The ingredient and chemical composition for the diets were as follows: $2100 \mathrm{kcal} / \mathrm{kg}$ energy, $12 \% \mathrm{CP}, 0.65 \% \mathrm{Ca}$, and $0.32 \% \mathrm{P}$. This diet meets the animals' growing nutritional needs. At each sampling time (30,60, 90, and 180 days), three individual pigs (male:female $=2: 1$ ) from each breed were slaughtered after $12 \mathrm{~h}$ fasting. One additional group of Bama Xiang pigs were sampled at day 300. The longissimus dorsi muscles (LM) were collected and divided into three portions for IMF measurement, determination of the other meat quality indices, and isolation of total RNA. The samples for RNA isolation were immediately frozen in liquid nitrogen and stored at $-80^{\circ} \mathrm{C}$ until further use.

\section{Determination of carcass traits and meat quality}

The carcass trait indices included live weight, carcass yield, backfat thickness, and loin eye area. Live weight was measured prior to slaughter, when the pigs were fasting but had access to water. Carcass yield is the ratio of slaughter live weight and live weight. Backfat thickness was measured as the fat thickness on the chest (between ribs 6 and 7). Loin eye area was measured between the 1 st and 2 nd penultimate thoracic longissimus cross-sectional width and height, using the following formula: loin eye muscle area $\left(\mathrm{cm}^{2}\right)=$ width $(\mathrm{cm}) \times$ height (cm) $\times 0.7$.

The meat quality indices included meat color, meat conductivity, shear force, and IMF content. Meat color was measured 45 min postmortem, using an OPTO-STAR meat color detector (Matthäus Co., Nobitz, Germany) on $1 \mathrm{~cm}$ diameter areas from each freshly cut LM muscle. Conductivity was determined at 10 points of the LM at the 10th rib for each pig using an LF-STAR muscle conductivity detector (Matthäus Co.). Shear force was measured using a C-LW3 muscle tenderness instrument (Engineering by College of Northeast Agricultural University, China) on 10 meat samples from each freshly cut LM, 45 min postmortem. IMF content was measured by petroleum ether extraction, $24 \mathrm{~h}$ after slaughter on $100 \mathrm{~g} \mathrm{LM}$ samples (Fortin et al., 2005).

\section{Total RNA extraction and reverse transcription}

Total RNA was isolated from the LM using the Trizol Reagent procedure (Invitrogen Life Technologies, Carlsbad, CA, USA). RNA purity and concentration were determined using a spectrophotometer at 260 and $280 \mathrm{~nm}$. Transcription was performed with $1.0 \mu \mathrm{g}$ total RNA, using a PrimeScript ${ }^{\mathrm{TM}}$ RT Reagent Kit with gDNA Eraser (Takara Biotechnology Co. Ltd., Dalian, China).

\section{Quantitative real-time polymerase chain reaction (PCR)}

Quantitative real-time PCR was performed using Roche LightCycler ${ }^{\circledR} 480$ PCR system (Roche Co., Rotkreuz, Switzerland) and LightCycler ${ }^{\circledR} 480$ SYBR Green I Master (Roche Co.). MyHC I, MyHC IIa, MyHC IIx, MyHC IIb, 18S rRNA, PGC-1 $\alpha$, and AMPK primers used for the PCR are presented in Table 1. The total PCR volume $(20 \mu \mathrm{L})$ consisted of $10.0 \mu \mathrm{L}$ SYBR 
Green I Master, $5.0 \mu \mathrm{L}$ cDNA, $4.0 \mu \mathrm{L}$ doubled-distilled water, $0.5 \mu \mathrm{L}$ upper primer $(10 \mu \mathrm{M})$, and $0.5 \mu \mathrm{L}$ lower primer $(10 \mu \mathrm{M})$. The PCR was run under the following conditions: $95^{\circ} \mathrm{C}$ for $5 \mathrm{~min}$, followed by 40 cycles of $10 \mathrm{~s}$ at $95^{\circ} \mathrm{C}$ and $10 \mathrm{~s}$ at $60^{\circ} \mathrm{C}$. All results were normalized to the $18 \mathrm{~S}$ rRNA levels and gene expression was analyzed using the $2^{-\Delta \Delta C t}$ method (Livak and Schmittgen, 2001). All experiments were repeated in triplicate.

Table 1. Primer sequences for real-time quantitative PCR.

\begin{tabular}{|c|c|c|c|}
\hline Genes & Primer sequence $\left(5^{\prime} \rightarrow 3^{\prime}\right)$ & Amplicon size (bp) & Reference \\
\hline \multirow[t]{2}{*}{ MyHC I } & F: GGCCCCTTCCAGCTTGA & \multirow[t]{2}{*}{63} & \multirow[t]{2}{*}{ Guo et al., 2011} \\
\hline & R: TGGCTGCGCCTTGGTTT & & \\
\hline \multirow[t]{2}{*}{ MyHC IIa } & F: TTAAAAAGCTCCAAGAACTGTTTCA & \multirow[t]{2}{*}{100} & \multirow[t]{2}{*}{ Guo et al., 2011} \\
\hline & R: CCATTTCCTGGTCGGAACTC & & \\
\hline \multirow[t]{2}{*}{ MyHC IIx } & F: AGCTTCAAGTTCTGCCCCACT & \multirow[t]{2}{*}{76} & \multirow[t]{2}{*}{ Guo et al., 2011} \\
\hline & R: GGCTGCGGGTTATTGATGG & & \\
\hline \multirow[t]{2}{*}{ MyHC IIb } & F: CACTTTAAGTAGTTGTCTGCCTTGAG & \multirow[t]{2}{*}{80} & \multirow[t]{2}{*}{ Guo et al., 2011} \\
\hline & R: GGCAGCAGGGCACTAGATGT & & \\
\hline \multirow[t]{2}{*}{ 18S rRNA } & F: CCCACGGAATCGAGAAAGAG & \multirow[t]{2}{*}{122} & \multirow[t]{2}{*}{ Guo et al., 2011} \\
\hline & R: TTGACGGAAGGGCACCA & & \\
\hline \multirow[t]{2}{*}{ PGC-1 $\alpha$} & F: GTGTCGCCTTCTTGTTCTTCTTTT & \multirow[t]{2}{*}{92} & \multirow[t]{2}{*}{ This study } \\
\hline & R: CGCATCCTTTGGGGTCTTT & & \\
\hline \multirow[t]{2}{*}{ AMPK } & F: TGTGACAAGTACATACTCCAA & \multirow[t]{2}{*}{132} & \multirow[t]{2}{*}{ This study } \\
\hline & R: GATCTCTGTGGAGTAGCAG & & \\
\hline
\end{tabular}

\section{Data analysis}

Relative mRNA was investigated by real-time PCR and was expressed relative to a control (Landrace pigs). The results are reported as means \pm SE. Comparisons between different breeds were made by $t$-tests (SPSS 18.0) and correlation analyses were made by Pearson correlation analysis (SPSS 18.0).

\section{RESULTS}

\section{Carcass traits and meat quality between Bama Xiang and Landrace pigs}

The appearance of an adult Bama Xiang pig is shown in Figure 1. Compared with the Landrace pig, the Bama Xiang pigs have conspicuous markings with a black head and hip area, whereas the Landrace pig is completely white. Weights were compared between Bama Xiang and Landrace pigs at the same age (30,60, 90, and 180 days). Day 300, which is the marketing age for Bama Xiang pigs, was investigated only for Bama Xiang pigs. From the age of 30 to 180 days, Landrace pigs gained about $68 \mathrm{~kg}$, while Bama Xiang pigs only gained about $15 \mathrm{~kg}$ (Figure 2). From the age of 30 to 300 days, Bama Xiang pigs gained about 36 $\mathrm{kg}$ (Figure 2). Regardless of age, Bama Xiang pigs weighed significantly less than Landrace pigs $(\mathrm{P}<0.01)$. This illustrates that the Landrace pigs had a higher weight increase than Bama Xiang pigs.

Carcass traits and meat quality were compared between Bama Xiang and Landrace pigs at 180 days ( 300 days was measured only for Bama Xiang pigs). There was no difference in carcass yield $(\mathrm{P}>0.05)$. In contrast, backfat thickness and loin eye muscle area differed among breeds $(\mathrm{P}<0.01)$; at the same age, Bama Xiang pigs showed higher backfat thickness but lower loin eye muscle area (Table 2). 


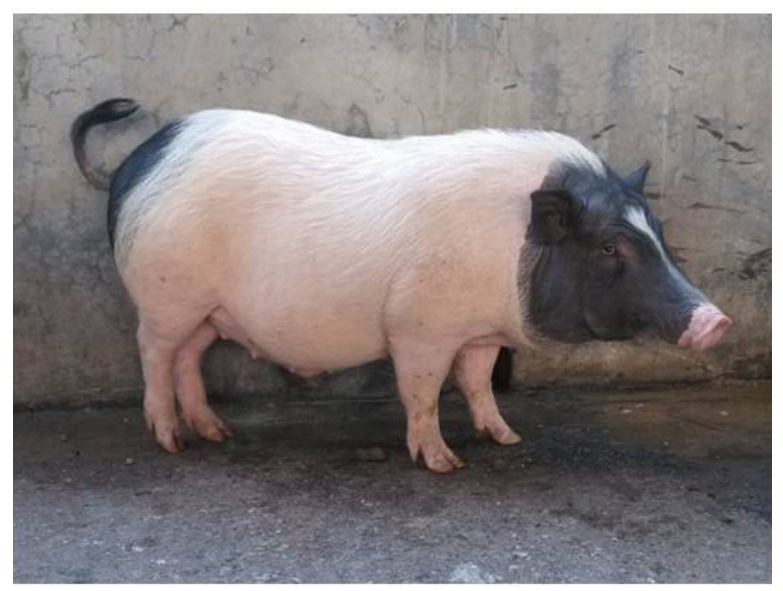

Figure 1. Appearance of the Bama Xiang pig at 12 months of age.

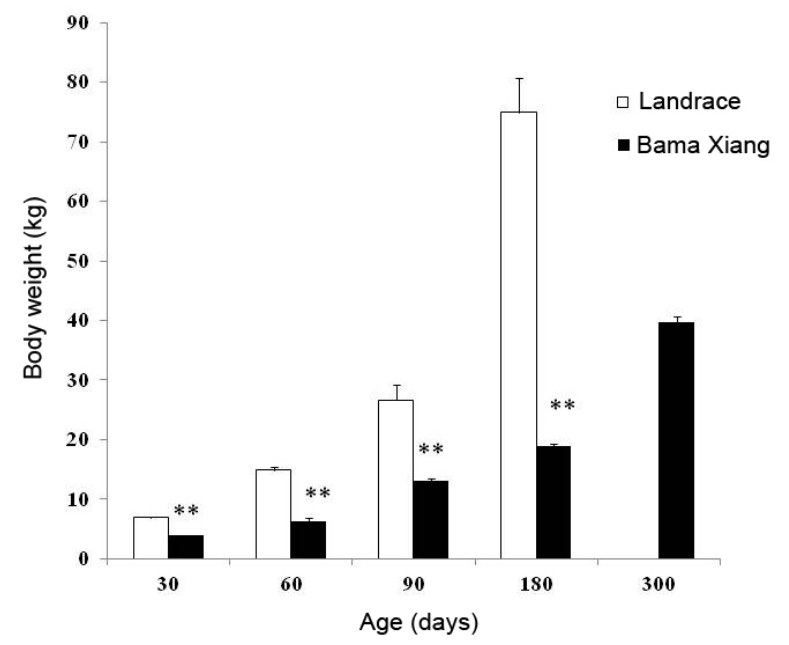

Figure 2. Body weight of Bama Xiang and Landrace pigs over time. Landrace pigs gained weight faster than Bama Xiang pigs. Data for each breed are reported as means \pm SE. $* * \mathrm{P}<0.01$.

Table 2. Characteristics of carcass traits and meat quality in Landrace (180 days) and Bama Xiang pigs (180 and 300 days).

\begin{tabular}{l|c|c|c}
\hline Item & Landrace $(180$ days $)$ & Bama Xiang (180 days) & Bama Xiang (300 days) \\
\hline Carcass yield $(\%)$ & $73.54 \pm 1.72$ & $76.89 \pm 1.73$ & $69.39 \pm 0.73$ \\
\hline BF $\left(\mathrm{cm}^{2}\right)$ & $1.47 \pm 0.21^{\mathrm{b}}$ & $4.23 \pm 0.15^{\mathrm{a}}$ & $4.70 \pm 0.57^{\mathrm{a}}$ \\
\hline LA $\left(\mathrm{cm}^{2}\right)$ & $36.58 \pm 2.37^{\mathrm{a}}$ & $13.63 \pm 0.40^{\mathrm{b}}$ & $15.13 \pm 1.65^{\mathrm{b}}$ \\
\hline Color & $63.44 \pm 0.88$ & $64.65 \pm 2.80$ & $64.11 \pm 1.68$ \\
\hline Conductivity $(\mathrm{ms})$ & $4.24 \pm 0.63^{\mathrm{a}}$ & $2.93 \pm 0.48^{\mathrm{a}}$ & $1.26 \pm 0.05^{\mathrm{b}}$ \\
\hline SF $(\mathrm{N})$ & $17.89 \pm 0.96$ & $16.13 \pm 1.26$ & $16.66 \pm 0.73$ \\
\hline IMF $(\%)$ & $2.32 \pm 0.43^{\mathrm{b}}$ & $6.05 \pm 0.57^{\mathrm{a}}$ & $7.44 \pm 0.22^{\mathrm{a}}$ \\
\hline
\end{tabular}

Superscripted letters within a row indicate significant differences $(\mathrm{P}<0.01)$. Results are reported as means $\pm \mathrm{SE}$ of three pigs. $\mathrm{BF}=$ backfat thickness, $\mathrm{LA}=$ loin eye muscle area, $\mathrm{SF}=$ shear force, $\mathrm{IMF}=$ intramuscular fat. 
According to the reference standard of OPTO values (OPTO-wert) for meat color, values $\geq 63$ indicate excellent meat, $53 \leq$ OPTO-wert $<63$ indicate good meat, and values $<53$ indicate poor meat. Our results indicated that the meat color for 180-day Landrace and Bama Xiang pigs, and 300-day Bama Xiang pigs were all excellent, and there were no significant differences $(\mathrm{P}>0.05)$ among them (Table 2). At 300 days, Bama Xiang pigs exhibited lower conductivity than both Bama Xiang and Landrace pigs at 180 days $(\mathrm{P}<0.01)$, whereas no significant difference was found between the two breeds at 180 days. Although not statistically significant $(\mathrm{P}>0.05)$, the shear force at 180 and 300 days in Bama Xiang pigs was lower than that of Landrace pigs at 180 days. Bama Xiang pigs showed higher IMF content at both 180 and 300 days, compared to Landrace pigs at 180 days $(\mathrm{P}<0.01)$.

\section{MyHC fiber-type composition in Bama Xiang and Landrace pigs}

We analyzed the MyHC fiber-type composition of Bama Xiang and Landrace pig breeds at different developmental stages by detecting the expression of MyHC isoform types I, IIa, IIx, and IIb. When MyHC isoforms were compared at 30 days, we found that the expression level of MyHC I was significantly higher in Bama Xiang pigs than in Landrace pigs $(\mathrm{P}<0.01)$, whereas the expression levels of MyHC IIx and IIb were significantly lower in Bama Xiang than in Landrace pigs $(\mathrm{P}<0.05)$. We found no significant difference in the expression level of MyHC IIa ( $\mathrm{P}>0.05)$ (Figure 3). At 60 days, Bama Xiang pigs exhibited higher expression levels of MyHC I and IIa, but lower expression level of MyHC IIb compared to Landrace pigs $(\mathrm{P}<0.01)$. No difference was found in the level of MyHC IIx $(\mathrm{P}>0.05$; Figure 3$)$. At 90 days, Bama Xiang pigs exhibited lower expression levels of MyHC IIa and IIb compared to Landrace pigs $(\mathrm{P}<0.01)$, whereas no differences were found in MyHC I and IIx $(\mathrm{P}>0.05$; Figure 3). Finally, at 300 days Bama Xiang pigs exhibited higher expression levels of MyHC I, IIa, and IIx than both Bama Xiang and Landrace pigs at 180 days $(\mathrm{P}<0.01)$, whereas Bama Xiang pigs exhibited significantly lower expression levels of MyHC IIb at 300 days compared to Landrace pig and Bama Xiang pigs at 180 days $(\mathrm{P}<0.05)$. In the comparisons between Bama Xiang and Landrace pigs at 180 days, there were no differences in MyHC I and IIb (P > 0.05), but Bama Xiang pigs exhibited higher expression levels of MyHC IIa and IIx compared to Landrace pigs $(\mathrm{P}<0.01$; Figure 3$)$.

\section{Correlations between MyHC fiber types and carcass and meat quality traits}

The correlation analyses illustrating the relationships between MyHC gene expression levels and selected carcass and meat quality are shown in Table 3. MyHC I gene expression showed positive correlations with both backfat thickness and IMF content $(\mathrm{P}<0.01)$. MyHC IIb was negatively correlated with IMF content $(\mathrm{P}<0.05)$ and positively correlated with carcass yield $(\mathrm{P}<0.05)$. No significant correlations between MyHC IIa and IIx were found with the selected carcass and meat quality traits $(\mathrm{P}>0.05)$.

\section{Comparison of key factors regulating muscle fiber type between Bama Xiang and Landrace pigs}

We analyzed the key factors regulating muscle fiber type between Bama Xiang and Landrace pig breeds at 180 days (and 300 days for Bama Xiang pigs). The results showed 
that in Bama Xiang pigs, gene expression of both PGC-1 $\alpha$ and AMPK at 180 and 300 days was higher compared to that in Landrace pigs at 180 days $(\mathrm{P}<0.01$; Figure 4$)$. These results indicate that PGC- $1 \alpha$ and AMPK might be two of the key factors regulating muscle fiber type in Bama Xiang pigs.
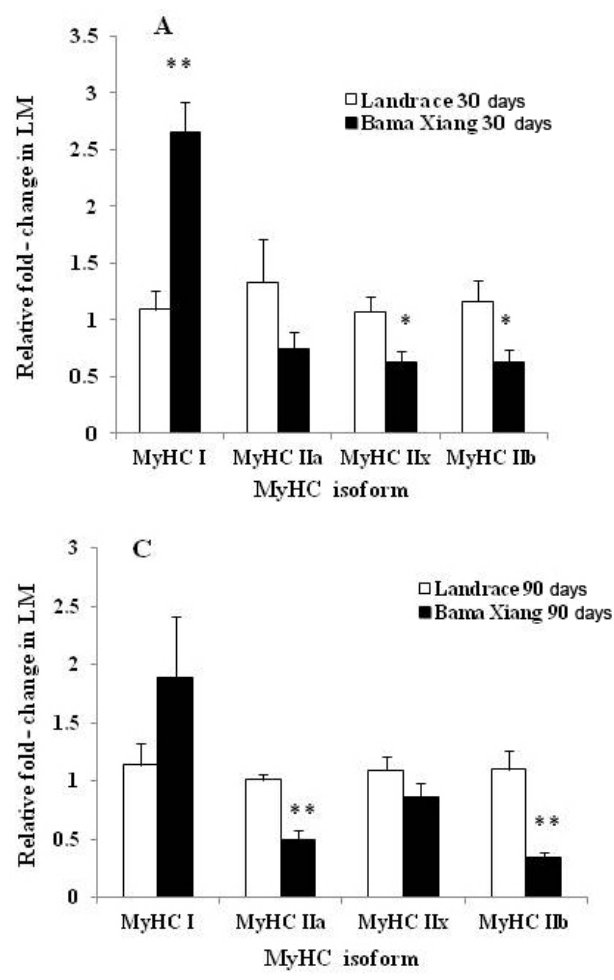
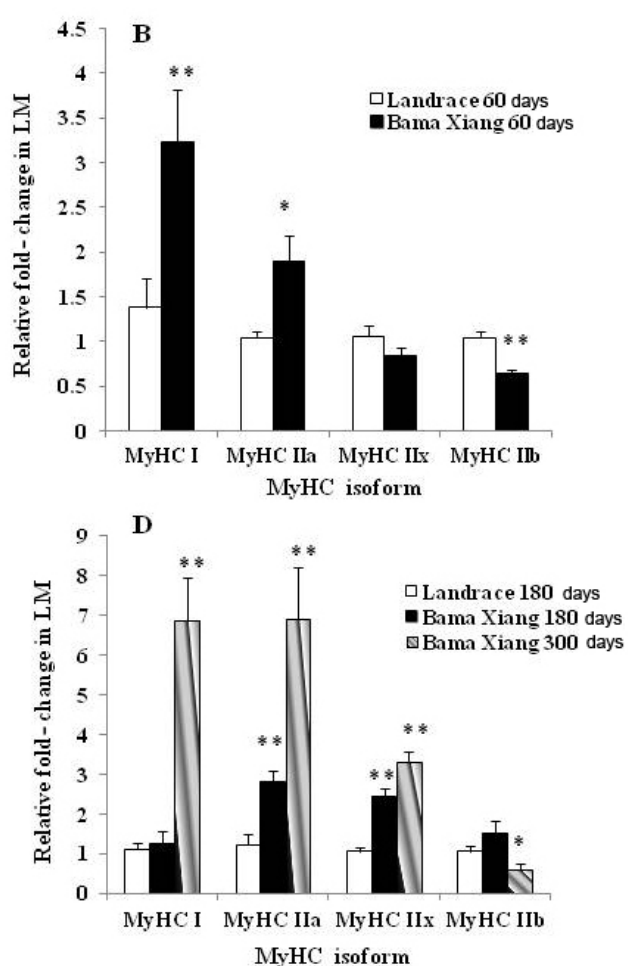

Figure 3. Relative mRNA expression of myosin heavy chain (MyHC) isoform genes in longissimus dorsi muscle (LM) of Bama Xiang and Landrace pigs at different ages. A.-C. show gene expression of MyHC isoform of Bama Xiang and Landrace pigs at 30, 60, and 90 days, respectively. D. shows gene expression of MyHC isoform of Bama Xiang (180 and 300 days) and Landrace pigs (180 days). Relative mRNA was investigated by real-time PCR and was expressed relative to a control (Landrace pigs). The given values are reported as means $\pm \mathrm{SE}$ of three pigs that had been normalized to $18 \mathrm{~S}$ rRNA. $* * \mathrm{P}<0.01, * \mathrm{P}<0.05$.

Table 3. Pearson correlation coefficients between MyHC gene expression and selected carcass and meat quality characteristics of LM.

\begin{tabular}{l|c|c|c|c|c|c|c}
\hline & Body weight & Carcass yield & BF & LA & Color & SF & IMF \\
\hline MyHC I & -0.104 & -0.885 & $0.630^{* *}$ & -0.469 & 0.085 & -0.246 & $0.722^{* *}$ \\
\hline MyHC IIa & -0.257 & -0.739 & 0.805 & -0.676 & 0.332 & -0.482 & 0.427 \\
\hline MyHC IIx & 0.248 & -0.439 & 0.967 & -0.900 & 0.657 & -0.771 & 0.227 \\
\hline MyHC IIb & -0.263 & $1.000^{*}$ & -0.169 & -0.024 & 0.414 & -0.260 & $-0.684^{*}$ \\
\hline
\end{tabular}

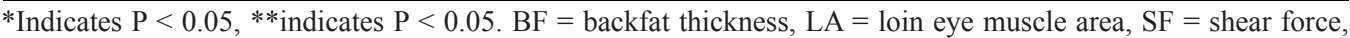
$\mathrm{IMF}=$ intramuscular fat. 


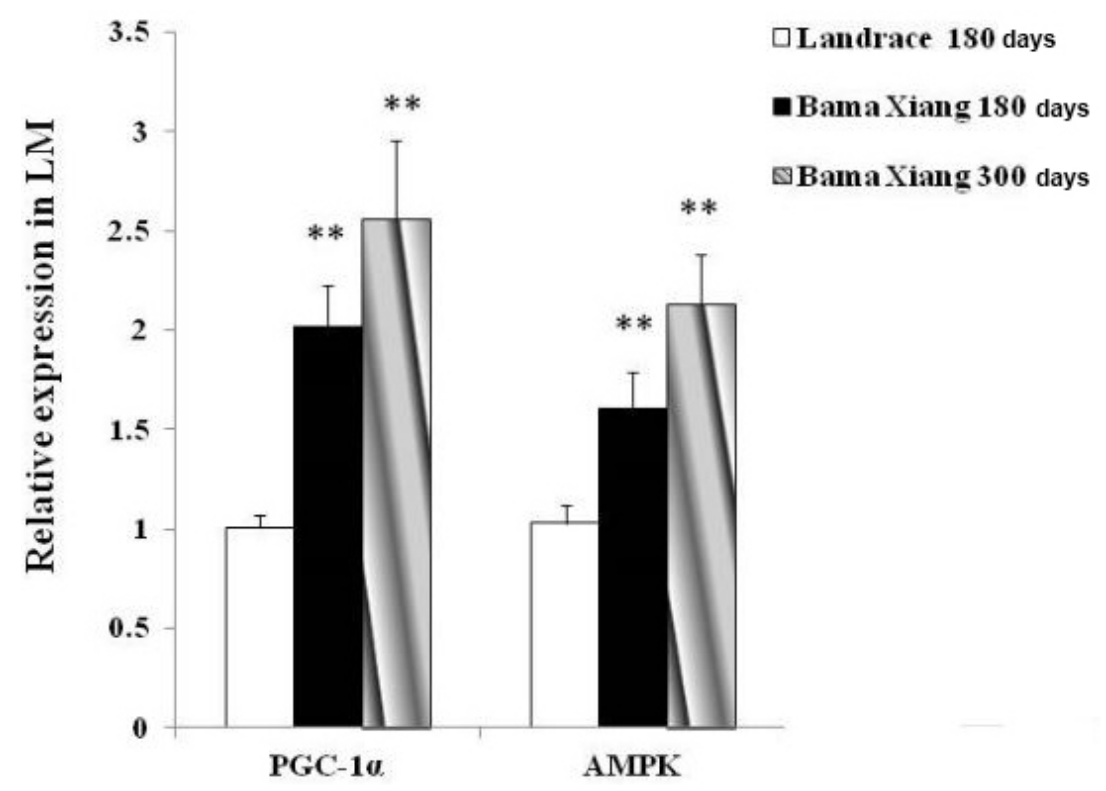

Figure 4. Relative mRNA expression of PGC-1 $\alpha$ and AMPK in longissimus dorsi muscle (LM) in Bama Xiang pigs (180 and 300 days) and Landrace pigs (180 days). Relative mRNA was investigated by real-time PCR and was expressed relative to a control (Landrace pigs). The given values are reported as means $\pm \mathrm{SE}$ of three pigs that had been normalized to $18 \mathrm{~S}$ rRNA. ${ }^{* *} \mathrm{P}<0.01$.

\section{DISCUSSION}

In this study, we first compared the carcass traits and meat quality features between Bama Xiang and Landrace pigs. In China, the Bama Xiang pig, a type of local fatty pig, is famous for its slow growth rate, high IMF contents, and excellent meat quality. By contrast, the Landrace pig is a popular breed with a fast growth rate, low IMF contents, and poor meat quality. As expected, we found that Bama Xiang pigs exhibited a lower growth rate compared to Landrace pigs, at all tested time points (30, 60, 90, and 180 days). Furthermore, we found that Bama Xiang pigs exhibited greater backfat thickness and IMF content, but a reduced loin eye muscle area and lower conductivity at 180 days. Our results showing that the Chinese local fatty pigs have superior meat quality are consistent with those of previous studies (Yang et al., 2005; Hu et al., 2008; Dai et al., 2009; Shan et al., 2010; Guo et al., 2011).

Factors such as breed, developmental stage, nutrition, slaughter condition, and meat processing methods, have been found to affect meat quality. Many previous reports have shown a relationship between muscle fiber type and meat quality (Kim et al., 2008; Ryu et al., 2008; Choi and Kim, 2009). Muscle fibers are the basic muscle units, which directly affect meat quality, especially tenderness, flavor, juiciness, water-holding capacity, etc. Therefore, muscle fiber type is considered to be one of the major factors influencing meat quality. However, to date, there are no reports on the muscle fiber composition in Bama Xiang pigs. Many studies have been conducted using tissue enzymatic methods to define muscle fiber types (such as 
myosin ATPase and succinate dehydrogenase staining), but these methods are unable to define the muscle fiber types accurately, and different staining methods yield different conclusions (Chikuni et al., 2001; Eggert et al., 2002; Chang et al., 2003). The current opinion is that the best method for defining the muscle fiber type is molecular identification on the basis of MyHC expression (Choi and Kim, 2009; Park et al., 2009; Schiaffino and Reggiani, 2011). In our study, we used quantitative real-time PCR, to investigate the compositional differences and developmental changes in LM fiber types between Bama Xiang pigs and Landrace pigs. As such, this constitutes the first study of muscle fiber type between the two breeds using molecular biology methods. An increased expression of MyHC I was observed at 30 and 60 days in Bama Xiang, compared with Landrace pigs. This pattern was especially evident at 300 days, in Bama Xiang, compared to both Bama Xiang and Landrace pigs at 180 days. By contrast, the expression levels of glycolytic fibers (MyHC IIb) were lower in Bama Xiang compared to Landrace pigs at all ages. At the marketing age (180 days for Landrace and 300 days for Bama Xiang pig), the contents of both oxidative (type I and IIa) and intermediate muscle fibers (type IIx) in Bama Xiang pigs, were significantly higher than in Landrace pigs. These results were consistent with those found in previous studies of Chinese local pigs including Meishan (Lefaucheur et al., 2004), Erhualian (Yang et al., 2005), Laiwu (Hu et al., 2008), Jinhua (Guo et al., 2011), and Tibetan pigs (Shen et al., 2014), in which the oxidative muscle fiber contents were higher and the glycolytic fiber contents lower than those in lean pigs. The Bama Xiang pigs grow slower and have a smaller body size, compared to Landrace pigs. This indicates that the pig breeds differ in the relative amount of muscle fiber types; fast growing pigs exhibit more glycolytic muscle fibers. Compared with lean pigs, the LM of Chinese local pigs exhibited higher contents of oxidative muscle fibers, which may be associated with their excellent meat and slow growth. Many studies have shown that oxidative muscle fibers are positively related with IMF and tenderness (Kim et al., 2008; Choi and Kim, 2009), whereas glycolytic muscle fibers are related with pale, soft, and exudative meat (Franck et al., 2007). Although breed is one of the most important factors in determining meat quality, the ultimate reason for the different meat qualities is differences in muscle fiber type. These results support the fact that muscle fiber type and composition may be the key factors determining the differences between different meat varieties.

In our study, we found that MyHC I gene expression was positively correlated with backfat thickness and IMF content, whereas MyHC IIb was negatively correlated with IMF content, and positively correlated with carcass yield. These results are consistent with those found in previous studies (Serra et al., 1998; Hu et al., 2008; Choi and Kim, 2009). IMF content is an important indicator of meat quality, affecting meat tenderness, water-holding capacity, shear force, flavor, and juiciness (Chambaz et al., 2003; Gao and Zhao, 2009; Lefaucheur, 2010). Previous studies have found that the relative magnitude of triglyceride and phospholipids in IMF in all types of muscle fibers were as follows: I $>$ IIa $>$ IIx $>\mathrm{IIb}$ (Leseigneur-Meynier and Gandemer, 1991; Alasnier et al., 1996; Malenfant et al., 2001). The deposition site of IMF is determined in relation to the specifics of the muscle fibers. Fat more easily deposits in muscles with a higher type I and type IIa contents (oxidative muscle fibers). In our study, we found that differences in muscle fiber type and content was one of the important factors contributing to the differences in slaughter performance and meat quality traits in Bama Xiang and Landrace pigs. The regulation of muscle fiber types and composition to achieve the best IMF contents will likely become a new research direction in fields aimed at improving pork quality and regulation. 
AMPK and PGC-1 $\alpha$ are both closely related to muscle fiber-type transformation. Exercise can induce transformation of muscle fiber types to oxidative muscle fiber types, and the muscle fiber-type transformation was found to be blocked in AMPK-deficient mice (Wojtaszewski et al., 2000; Chen et al., 2003; Röckl et al., 2007; Geng et al., 2010). Long-term injection of AMPK agonists can regulate transformation of mouse muscle fiber type to oxidized muscle fiber types (Suwa et al., 2003; Ljubicic et al., 2011). A previous study found an increase in the number and function of mouse mitochondria, as well as in oxidative muscle fiber type I, after overexpression of PGC-1 $\alpha$ in mouse muscle (Lin et al., 2002). AMPK can regulate the expression of PGC-1 $\alpha$, both directly and indirectly (Cantó et al., 2009). Previous studies on the relationships between AMPK, PGC-1 $\alpha$, and muscle fiber-type transformation have mostly focused on human and mouse. The data presented here, illustrating the relationship between AMPK, PGC-1 $\alpha$, and pig muscle fiber-type transformation, therefore represent a rare case. We analyzed the expression of AMPK, PGC-1 $\alpha$ in the LM of Bama Xiang and Landrace pigs at the marketing age and found that the PGC- $1 \alpha$ and AMPK gene expression of Bama Xiang pigs was higher than in Landrace pigs. This result was consistent with the observed differences in muscle fiber type at the marketing age between the breeds. This indicates that AMPK and PGC-1 $\alpha$ might be two key factors regulating muscle fiber type in pigs, similar to in human and mouse. The AMPK and PGC-1 $\alpha$ genes may play an important role in pig muscle fiber transformation, and may be the important regulatory factors in the observed muscle growth and developmental differences between the breeds. Therefore, the mechanism by which AMPK and PGC-1 $\alpha$ regulates muscle fiber type in pigs should be further studied. As the first study of the key factors regulating muscle fiber type in Bama Xiang and Landrace pigs, our results provide an important basis for further studies of the mechanism of muscle fiber type in these pigs.

In conclusion, the excellent meat quality, in particular the high IMF content in Bama Xiang pigs, was found to be related to its elevated type I oxidative muscle fiber content. In contrast, Landrace pig muscle contained more glycolytic type IIb muscle fibers, resulting in poorer meat quality. AMPK and PGC-1 $\alpha$ were identified as two potential key factors regulating muscle fiber type in pigs. The muscle fiber composition is one of the key differences leading to the observed differences in meat quality between Bama Xiang and Landrace pigs. The results in this study may provide a theoretical basis for further studies on the molecular mechanisms behind the excellent Bama Xiang pig meat quality.

\section{Conflicts of interest}

The authors declare no conflict of interest.

\section{ACKNOWLEDGMENTS}

Research supported by the National Natural Science Foundation of China (\#81360135 and \#31460606), the Guangxi Natural Science Foundation (\#2012GXNSFBA053041, \#2013GXNSFBA019077, and \#2014GXNSFAA118131), the Guangxi Universities Science Technology Research Project (\#2013YB004), the Guangxi University Postdoctoral Fund (\#B260001005) and the Guangxi Postdoctoral Special Fund (\#Y334001902 and \#Y334002005). 


\section{REFERENCES}

Alasnier C, Rémignon H and Gandemer G (1996). Lipid characteristics associated with oxidative and glycolytic fibres in rabbit muscles. Meat Sci. 43: 213-224. http://dx.doi.org/10.1016/S0309-1740(96)00015-0

Cantó C, Gerhart-Hines Z, Feige JN, Lagouge M, et al. (2009). AMPK regulates energy expenditure by modulating NAD metabolism and SIRT1 activity. Nature 458: 1056-1060. http://dx.doi.org/10.1038/nature07813

Chambaz A, Scheeder MR, Kreuzer M and Dufey PA (2003). Meat quality of Angus, Simmental, Charolais and Limousin steers compared at the same intramuscular fat content. Meat Sci. 63: 491-500. http://dx.doi.org/10.1016/S0309$\underline{1740(02) 00109-2}$

Chang KC, da Costa N, Blackley R, Southwood O, et al. (2003). Relationships of myosin heavy chain fibre types to meat quality traits in traditional and modern pigs. Meat Sci. 64: 93-103. http://dx.doi.org/10.1016/S0309-1740(02)00208-5

Chen ZP, Stephens TJ, Murthy S, Canny BJ, et al. (2003). Effect of exercise intensity on skeletal muscle AMPK signaling in humans. Diabetes 52: 2205-2212. http://dx.doi.org/10.2337/diabetes.52.9.2205

Chikuni K, Tanabe R, Muroya S and Nakajima I (2001). Differences in molecular structure among the porcine myosin heavy chain-2a, -2x, and -2b isoforms. Meat Sci. 57: 311-317. http://dx.doi.org/10.1016/S0309-1740(00)00107-8

Choi YM and Kim BC (2009). Muscle fiber characteristics, myofibrillar protein isoforms, and meat quality. Livest. Sci. 122: 105-118. http://dx.doi.org/10.1016/j.livsci.2008.08.015

Dai F, Feng D, Cao Q, Ye H, et al. (2009). Developmental differences in carcass, meat quality and muscle fibre characteristics between the Landrace and a Chinese native pig. S. Afr. J. Anim. Sci. 39: 267-273.

Eggert JM, Depreux FF, Schinckel AP, Grant AL, et al. (2002). Myosin heavy chain isoforms account for variation in pork quality. Meat Sci. 61: 117-126. http://dx.doi.org/10.1016/S0309-1740(01)00154-1

Fortin A, Robertson WM and Tong AK (2005). The eating quality of Canadian pork and its relationship with intramuscular fat. Meat Sci. 69: 297-305. http://dx.doi.org/10.1016/j.meatsci.2004.07.011

Franck M, Figwer P, Godfraind C, Poirel MT, et al. (2007). Could the pale, soft, and exudative condition be explained by distinctive histological characteristics? J. Anim. Sci. 85: 746-753. http://dx.doi.org/10.2527/jas.2006-190

Gao SZ and Zhao SM (2009). Physiology, affecting factors and strategies for control of pig meat intramuscular fat. Recent Pat. Food Nutr. Agric. 1: 59-74. http://dx.doi.org/10.2174/2212798410901010059

Geng T, Li P, Okutsu M, Yin X, et al. (2010). PGC-1 $\alpha$ plays a functional role in exercise-induced mitochondrial biogenesis and angiogenesis but not fiber-type transformation in mouse skeletal muscle. Am. J. Physiol. Cell Physiol. 298: C572-C579. http://dx.doi.org/10.1152/ajpcell.00481.2009

Guo J, Shan T, Wu T, Zhu LN, et al. (2011). Comparisons of different muscle metabolic enzymes and muscle fiber types in Jinhua and Landrace pigs. J. Anim. Sci. 89: 185-191. http://dx.doi.org/10.2527/jas.2010-2983

Hu H, Wang J, Zhu R, Guo J, et al. (2008). Effect of myosin heavy chain composition of muscles on meat quality in Laiwu pigs and Duroc. Sci. China C Life Sci. 51: 127-132. http://dx.doi.org/10.1007/s11427-008-0016-x

Kim NK, Lim JH, Song MJ, Kim OH, et al. (2008). Comparisons of longissimus muscle metabolic enzymes and muscle fiber types in Korean and western pig breeds. Meat Sci. 78: 455-460. http://dx.doi.org/10.1016/j.meatsci.2007.07.014

Lee SH, Joo ST and Ryu YC (2010). Skeletal muscle fiber type and myofibrillar proteins in relation to meat quality. Meat Sci. 86: 166-170. http://dx.doi.org/10.1016/j.meatsci.2010.04.040

Lefaucheur L (2010). A second look into fibre typing - relation to meat quality. Meat Sci. 84: 257-270. http://dx.doi. org/10.1016/j.meatsci.2009.05.004

Lefaucheur L, Ecolan P, Plantard L and Gueguen N (2002). New insights into muscle fiber types in the pig. J. Histochem. Cytochem. 50: 719-730. http://dx.doi.org/10.1177/002215540205000513

Lefaucheur L, Milan D, Ecolan P and Le Callennec C (2004). Myosin heavy chain composition of different skeletal muscles in Large White and Meishan pigs. J. Anim. Sci. 82: 1931-1941.

Leseigneur-Meynier A and Gandemer G (1991). Lipid composition of pork muscle in relation to the metabolic type of the fibres. Meat Sci. 29: 229-241. http://dx.doi.org/10.1016/0309-1740(91)90052-R

Lin J, Wu H, Tarr PT, Zhang CY, et al. (2002). Transcriptional co-activator PGC-1 a drives the formation of slow-twitch muscle fibres. Nature 418: 797-801. http://dx.doi.org/10.1038/nature00904

Livak KJ and Schmittgen TD (2001). Analysis of relative gene expression data using real-time quantitative PCR and the $2^{-\Delta \Delta C t}$ method. Methods 25: 402-408. http://dx.doi.org/10.1006/meth.2001.1262

Ljubicic V, Miura P, Burt M, Boudreault L, et al. (2011). Chronic AMPK activation evokes the slow, oxidative myogenic program and triggers beneficial adaptations in mdx mouse skeletal muscle. Hum. Mol. Genet. 20: 3478-3493. http:// dx.doi.org/10.1093/hmg/ddr265

Malenfant P, Joanisse DR, Thériault R, Goodpaster BH, et al. (2001). Fat content in individual muscle fibers of lean and obese subjects. Int. J. Obes. Relat. Metab. Disord. 25: 1316-1321. http://dx.doi.org/10.1038/sj.ijo.0801733

Genetics and Molecular Research 15 (2): gmr.15028379

CFUNPEC-RP www.funpecrp.com.br 
Park SK, Gunawan AM, Scheffler TL, Grant AL, et al. (2009). Myosin heavy chain isoform content and energy metabolism can be uncoupled in pig skeletal muscle. J. Anim. Sci. 87: 522-531. http://dx.doi.org/10.2527/jas.2008-1269

Pette D and Staron RS (2001). Transitions of muscle fiber phenotypic profiles. Histochem. Cell Biol. 115: 359-372.

Röckl KS, Hirshman MF, Brandauer J, Fujii N, et al. (2007). Skeletal muscle adaptation to exercise training: AMP-activated protein kinase mediates muscle fiber type shift. Diabetes 56: 2062-2069. http://dx.doi.org/10.2337/db07-0255

Ryu YC, Choi YM, Lee SH, Shin HG, et al. (2008). Comparing the histochemical characteristics and meat quality traits of different pig breeds. Meat Sci. 80: 363-369. http://dx.doi.org/10.1016/j.meatsci.2007.12.020

Schiaffino S and Reggiani C (2011). Fiber types in mammalian skeletal muscles. Physiol. Rev. 91: 1447-1531. http:// dx.doi.org/10.1152/physrev.00031.2010

Serra X, Gil F, Pérez-Enciso M, Oliver MA, et al. (1998). A comparison of carcass, meat quality and histochemical characteristics of Iberian (Guadyerbas line) and Landrace pig. Livest. Prod. Sci. 56: 215-223. http://dx.doi. org/10.1016/S0301-6226(98)00151-1

Shan T, Wu T, Reng Y and Wang Y (2009). Breed difference and regulation of the porcine adipose triglyceride lipase and hormone sensitive lipase by TNFalpha. Anim. Genet. 40: 863-870. http://dx.doi.org/10.1111/j.13652052.2009.01927.x

Shan T, Ren Y, Liu Y, Zhu L, et al. (2010). Breed difference and regulation of the porcine Sirtuin 1 by insulin. J. Anim. Sci. 88: 3909-3917. http://dx.doi.org/10.2527/jas.2010-2880

Shen L, Lei H, Zhang S, Li X, et al. (2014). Comparison of energy metabolism and meat quality among three pig breeds. Anim. Sci. J. 85: 770-779. http://dx.doi.org/10.1111/asj.12207

Suwa M, Nakano H and Kumagai S (2003). Effects of chronic AICAR treatment on fiber composition, enzyme activity, UCP3, and PGC-1 in rat muscles. J. Appl. Physiol. 95: 960-968. http://dx.doi.org/10.1152/japplphysiol.00349.2003

Wegner J, Albrecht E, Fiedler I, Teuscher F, et al. (2000). Growth- and breed-related changes of muscle fiber characteristics in cattle. J. Anim. Sci. 78: 1485-1496.

Wojtaszewski JF, Nielsen P, Hansen BF, Richter EA, et al. (2000). Isoform-specific and exercise intensity-dependent activation of 5'-AMP-activated protein kinase in human skeletal muscle. J. Physiol. 528: 221-226. http://dx.doi. org/10.1111/j.1469-7793.2000.t01-1-00221.x

Yang XJ, Zhao RQ, Chen J, Xu QF, et al. (2005). The developmental changes of myofibre types in LD muscle of Erhualian and Large White pigs. Chin. J. Vet. Sci. 25: 89-94. 